\title{
Influence of Hydraulic and Interference-fit Tool Holders on Tool Wear and Hole Quality in the Drilling of Al-Si Cylinder Heads
}

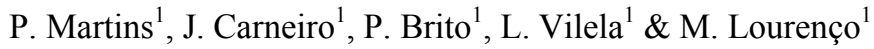 \\ ${ }^{1}$ Pontifical Catholic University of Minas Gerais Av. Dom José Gaspar 500, Belo Horizonte 30535-901, Brazil \\ Correspondence: P. Brito, Pontifical Catholic University of Minas Gerais Av. Dom José Gaspar 500, Belo \\ Horizonte 30535-901, Brazil. Tel: 55-31-8392-8400. E-mail: ppbrito@gmail.com
}

Received: December 11, 2012

Accepted: January 4, 2012 Online Published: May 24, 2012

doi:10.5539/mer.v2n1p29

URL: http://dx.doi.org/10.5539/mer.v2n1p29

\begin{abstract}
The present work compares the performance hydraulic and interference-fit tool holders in the machining of Al-Si cylinder head components produced by pressure casting for the automotive industry by analyzing tool wear as well as geometry, roughness and tolerance of the produced holes. Uncoated WC + Co cutting tools were applied and the drilling operations were carried out at a Hüller computer numerical controlled machining center. Tool wear was characterized by applying optical and scanning electron microscopy and geometry of the holes was followed for parts 1 to 11500 . The investigations revealed that, while no significant difference in tool wear could be detected, better results with respect to hole diameter, roundness and surface roughness were obtained for the drills fixed by thermal interference.
\end{abstract}

Keywords: wear, drilling, Al-Si alloy, hole quality, interference-fit

\section{Introduction}

$\mathrm{Al}$ alloys are used in a number of industry applications due to their low density, elevated mechanical strength and good machinability. The addition of Si to $\mathrm{Al}$ decreases its melting point and improves abrasion resistance of the component. Al-Si alloys are applied in the production of combustion engine components, which require good machinability, fluidity and low contraction tendency in pressure casting (Trent \& Wright, 2000). During machining operations, tool wear is low due to the elevated heat conduction coefficients of Al-Si alloys and due to the application of lower cutting forces when compared with other engineering materials (Cotterell \& Kelly, 2002).

Among traditional machining processes, drilling is one of the most common metal cutting techniques, corresponding to approximately $33 \%$ of all machining operations (Ertnuc \& Oysu, 2004). One of the main factors which affect the quality of a hole is the stiffness of the cutting tool, since errors may arise due to deviation or abnormal rotation of the drill, or deflection of the cutting tool due to force unbalances (Kallidas et al., 2001). In the specific case of Al-Si alloys, tool performance is further impaired by $\mathrm{Al}$ adhesion on the cutting tool (Coldwell et al., 2004; Hu \& Chou, 2007; Bhowmick \& Alpas, 2008).

An important part of the drilling operation, which impacts on the stiffness of the cutting tool, is the fixing of the cutting tool to the machine spindle, which is accomplished by applying an appropriate tool holder (Abele, 2010). Two common fixing methods involve hydraulic forces and the interference produced by heating ("shrink-fit" or interference-fit). In the hydraulic fixing system, a cylindrical dilating screw plug is caused to expand by injection of oil. In the thermal fixing system, the mandrill is heated, dilated and the tool is mounted with an interference of $0,025 \mathrm{~mm}$ to $0,050 \mathrm{~mm}$. The necessary heating can be produced by hot air, electrical induction or flame (Fiedler \& Würz, 2001). Tool mounting by thermal interference produces higher mechanical stiffness when compared to hydraulic tool holders (Schmitz et al., 2007; Houming et al., 2008; Zhang et al., 2000), allows for elevated torque transmission and generates concentricity errors of the order of $4 \mu \mathrm{m}$ (Arnone, 1998). On the other hand, costs involved in the thermal fixing system are higher and exchange of cutting tools is made more difficult (Schulz, 1996).

The objective of the present work is to provide a systematic comparison of the performance of hydraulic and interference-fit tool holders in the drilling of Al-Si alloy cylinder heads, investigating whether the higher mechanical stiffness of the thermal fixing results in improvements of hole quality or decrease in tool wear. 


\section{Experimental Procedure}

\subsection{Materials}

The materials used in the present work were Al-Si cylinder heads produced by pressure casting. A sample specimen is presented in Figure 1, where the drilled holes are indicated by the arrows. Chemical composition of the alloy is given in Table 1 (values are indicated in weight percent). Samples for microstructure analysis by Optical Microscopy were taken in the form of $30 \times 30 \mathrm{~mm}$ discs and were etched in a $1 \mathrm{vol} . \% \mathrm{HF}, 2.5 \mathrm{vol} . \% \mathrm{HNO}_{3}$, $1.5 \mathrm{vol} . \% \mathrm{HCl}, 95 \mathrm{vol} . \%$ distilled water solution for 5 hours. The specimens thus treated were analyzed in a Leitz optical microscope with a 200X magnification. The microstructure (presented in Figure 2) consisted of both Al-rich $\alpha$-phase and intermetallic eutectic phase. According to Teer and co-workers (Teer et al., 2005) this intermetallic phase is either $\mathrm{Al}_{5} \mathrm{Cu}_{2} \mathrm{Mg}_{2} \mathrm{Si}_{6}$ or $\mathrm{Al} 15(\mathrm{FeMn})_{3} \mathrm{Si}_{6}$.

Table 1. Chemical composition of the Al-Si alloy (values given in weight percent)

\begin{tabular}{llllllllllll}
\hline Element & $\mathrm{Al}$ & $\mathrm{Si}$ & $\mathrm{Cu}$ & $\mathrm{Mg}$ & $\mathrm{Mn}$ & $\mathrm{Ti}$ & $\mathrm{Fe}$ & $\mathrm{Zn}$ & $\mathrm{Ni}$ & $\mathrm{Pb}$ & $\mathrm{Sn}$ \\
\hline Composition (wt.\%) & 86.8 & 7.76 & 3.11 & 0.36 & 0.40 & 0.02 & 0.74 & 0.56 & 0.03 & 0.05 & 0.02 \\
\hline
\end{tabular}

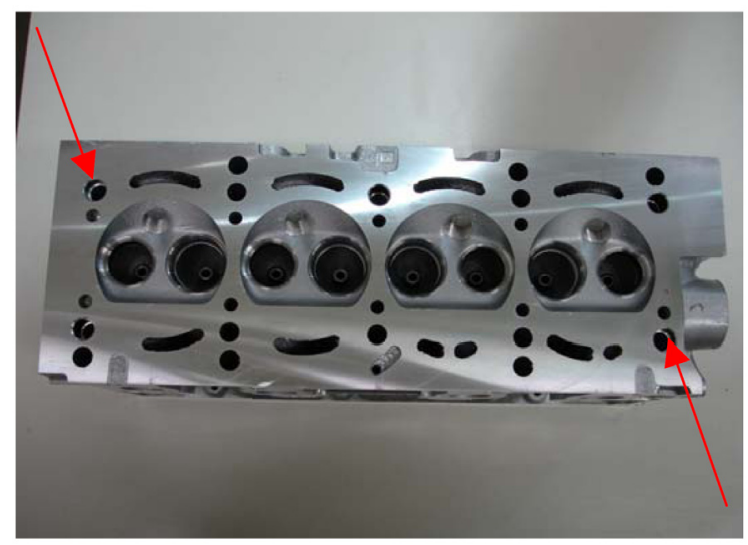

Figure 1. Cylinder head components used in the present work. Locations of the drilled holes are indicated by the arrows

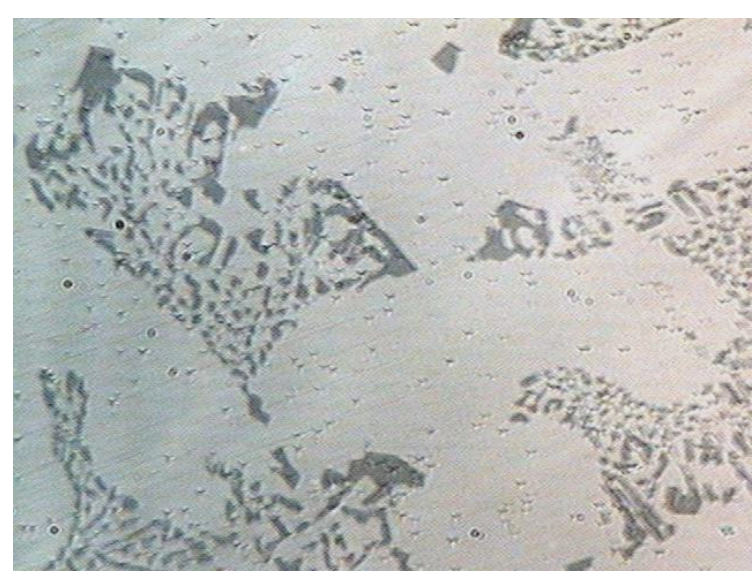

Figure 2. Microstructure of the Al-Si alloy, evidencing the light Al-rich $\alpha$-phase and the dark eutectic phase (magnification: 200X) 


\subsection{Methods}

Prior to drilling, the cylinder head specimens were machined in order to produce a $10.50 \mathrm{~mm}$ preliminary hole. Special care must be taken in order to ensure that first contact of the tool with the pre-hole is equal in all cutting edges. Nevertheless, the cutting may become irregular due to de-alignment of the pre-drilling tool axis, shape deviation, drill beating error and drill fixing problems at the machine-tool spindle.

The Al-Si cylinder heads were machined at a Siemens 840D Hüller machining center equipped with numerical command. In order to evaluate the impact of the different fixation systems on tool wear, the cutting tool was mounted using both thermal and hydraulic fixation systems. Uncoated hard metal (WC $+\mathrm{Co}$ ) cutting tools were applied with parallel rod, $\mathrm{H} 7$ allowance, first diameter tip angle of $145^{\circ}\left(10^{\circ}\right.$ clearance angle $)$, second diameter tip angle of $90^{\circ}\left(8^{\circ}\right.$ clearance angle) and drill diameter of $12.150 \mathrm{~mm}(+0.025+0.007)$. Housing of the drill to both hydraulic and thermal tool holders was accomplished by applying a semi-automatic Speroni fixation device. In both situations, the HSK63 chuck was used.

A cutting speed of $289 \mathrm{~mm} / \mathrm{min}$ with $8000 \mathrm{rpm}$ rotation was applied, with cutting depth of $0,05 \mathrm{~mm}$ and $0,36 \mathrm{~mm} /$ rotation feed rate. A HOCUT B 205D with $6 \%$ to $8 \%$ concentration and 30 bar pressure cutting fluid was used and the drilled holes were $8 \mathrm{~mm}$ deep. Upon completion of the drilling operations, the pieces were cooled to room temperature and submitted to metrology analysis. Specimens 1, 50, 100, 150, 200, 250, 300, 350, $400,500,1000,1500,2000,3500,5000,6500,8000,11500$ were taken in order to measure hole diameter and roundness. The radial beating error of the cutting tool was also measured for both fixation systems for the same samples. Measurements were performed at a distance corresponding to $127 \mathrm{~mm}$ of the HSK cone with respect to the drill tip. The measurements were carried out in a Mitutoyo dial indicator with $1 \mu \mathrm{m}$ resolution. Surface roughness parameters $R_{a}$ and $R_{z}$ were evaluated using a Taylor Hobson Form-Talysurf series equipment equipped with Gaussian coarseness filter, $0.8 \mathrm{~mm}$ cut-off and $4.8 \mathrm{~mm}$ length.

Analysis of tool wear and Al-Si deposition on the cutting tool in both hydraulic and thermal fixation systems was performed by applying OM and Scanning Electron Microscopy (SEM). Assessment of the wear level was made by measuring the distance between the cutting edge and the maximum color contrast width verified at the microscope in order to obtain the maximum wear-land width $\left(\mathrm{VB}_{\max }\right)$. The observed wear is the average of the thickness values measured on both faces. Analysis of the material deposition on the tool was performed in a Philips XL30 scanning electron microscope equipped with an Energy Dispersive X-ray Spectrometer (EDS) for chemical composition analysis. Removal of adhered Al-Si material was accomplished by cleansing the tools with a 10vol.\% NaOH, 90vol.\% water solution for $24 \mathrm{~h}$.

\section{Results and Discussion}

The evolution of tool beating error for both hydraulic and interference-fit systems after drilling parts 1 to 11500 is presented in Figure 3. No consistent growth of beating error with respect to the number of drills can be noticed for parts 1 to 6500. Initially, from parts 1 to 500 (which corresponds to approximately 6 hours of machining), the interference fitted tool exhibited an average beating error value of $0.002 \pm 0.0001 \mathrm{~mm}$ in comparison with $0.004 \pm 0.005 \mathrm{~mm}$ observed for the tool fixed with the hydraulic tool holder. However, upon increasing the number of machined parts, probably due to acceleration of tool wear, a sharp rise in beating error is observed for the tool fixed by hydraulic fit (from $0.004 \mathrm{~mm}$ after 5000 parts to 0.010 after 6500 parts). A similar increase is noticed for the tool fixed by interference fit (from $0.004 \mathrm{~mm}$ after 8000 parts to $0.007 \mathrm{~mm}$ after 8000 parts).

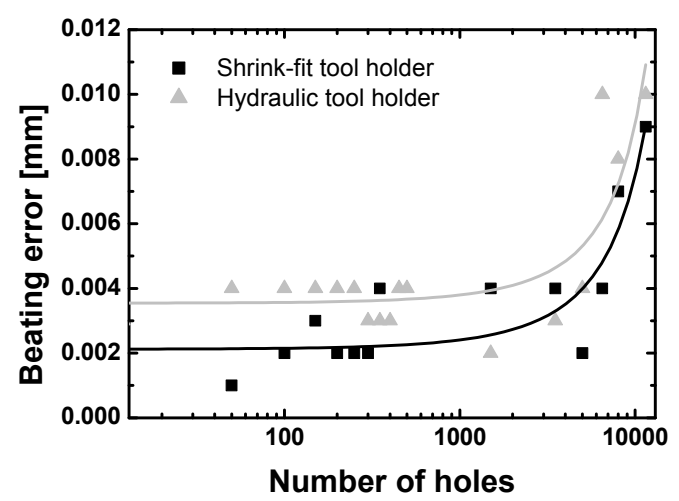

Figure 3. Evolution of tool beating error with respect to the number of drills for parts 1 to 11500 
The plot of $\mathrm{VB}_{\max }$ with respect to the number of machined parts is presented in Figure 4. The flank wear behavior of tools fixed using the interference and hydraulic tool holder is, in both cases, similar to the three-stage pattern described by Harris and co-workers (Harris et al., 2003). In Stage I, a rapid rise in wear in the first seconds of cutting is observed. Stage II, which here encompasses parts 100 to 7000 , is characterized by a constant flank wear value. In Stage III, which precedes failure of the drill, flank wear rises again, probably due to an adhesive mechanism (Doyle et al., 1986; Harris et al., 2003). It can be noticed that while for both tool holders the last stage of tool flank wear starts after approximately 7000 holes, the wear rise in Stage III is higher for the tool fixed by the hydraulic tool holder.



Figure 4. Evolution of tool flank wear $\left(\mathrm{VB}_{\max }\right)$ with respect to the number of drills for parts 1 to 11500

The aspect of the outer corner flank wear land after drilling of 500 and 11500 parts with both tool holders is shown in the SEM micrographs presented in Figure 5(a-d). From the early stages of tool wear, Figure 5(a) and $5(\mathrm{~b})$, the presence of adhered material can be observed for both tools, as indicated by the dark arrows. The presence of $\mathrm{Al}$ and $\mathrm{Si}$ on the drills could also be confirmed by EDS. The images reveal variations of texture of the adhered material and lack of uniformity in wear thickness.
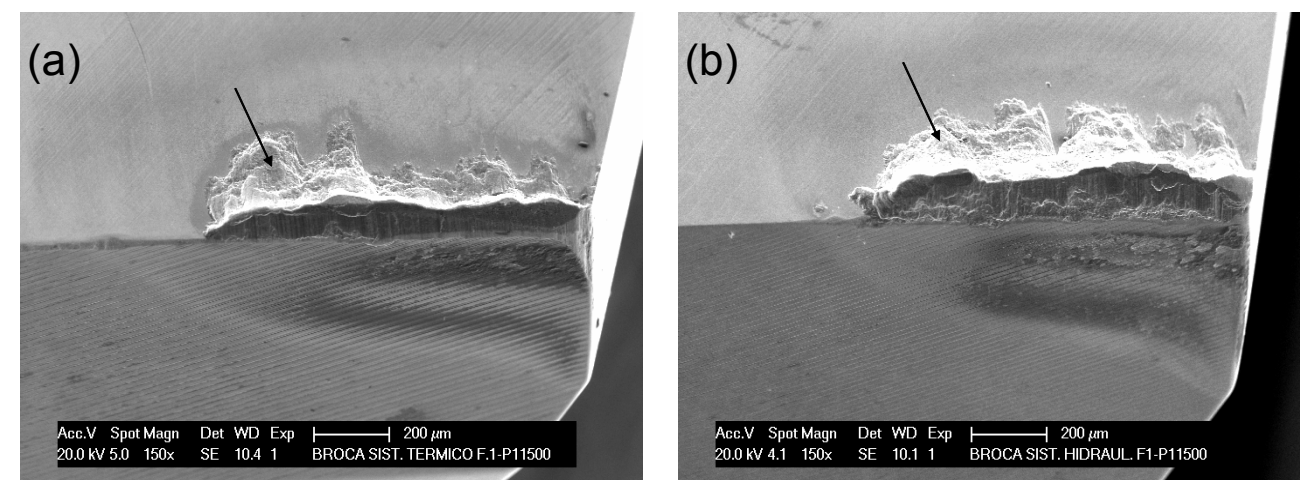

Figure 5. SEM images showing the outer corner flank wear land after drilling 11500 holes (150x magnification): (a) shrink-fit and (b) hydraulic tool-holder

Micrographs showing the aspect of the wear land after removal of the adhered material by treatment with the $\mathrm{NaOH}$ solution are presented in Figure 6(a-d). EDX analyses could confirm removal of the previously detected $\mathrm{Al}$ and Si. After 500 drills, Figure 6(a) and 6(b), it can be noticed that chipping of the tool tips took place together with minor wear sulks, for both fixing systems. Additionally, no signs of abrasive wear could be identified. In agreement with the results presented in Figure 4, no significant difference in wear can be noticed between both of the tools after drilling of 11500 parts.

After drilling of 11500 parts (Figure 6(c) and 6(d)), the region closest to the cutting edge exhibits most severe wear, with the presence of pits and abrasive scars which are characteristic of Stage III of wear behavior (Harris 
et al., 2003). The abrasive wear is caused my adhesion of material to the tool forming a deposit layer which is removed from the tool flank wear land during operation. In agreement with $\mathrm{Hu}$ and co-workers (Hu et al., 2007), the presence of ridges and grooves could be identified along the cutting direction, a further evidence of abrasion. These features could be caused by hard particles present in the workpiece.

The evolution of surface roughness parameters is presented in Figure 7(a) and 7(b) for the $R_{a}$ and $R_{z}$ parameters, respectively. Regarding the results plotted in Figure 7(a), it can be observed that, on average, the tool fixed by thermal interference exhibited lower $\mathrm{R}_{\mathrm{a}}$ values throughout the process when compared with the tool fixed using the hydraulic tool-holder, especially from part 1500 onwards. However, large oscillations in surface roughness can be noticed throughout the process, as also reported e.g. (Nouari et al., 2005). The evolution of the $\mathrm{R}_{\mathrm{z}}$ surface roughness parameter, which is an indicative assessment of the surface texture (Harris et al., 2003) is presented in Figure 7(b). No distinctive trend relating the number of holes and the surface roughness can be discerned, given the irregularity of the measured values. The oscillations in surface roughness probably occur because of the irregular nature of the material deposition on the drill and also due to the fact that the Al-Si particles continuously adhere and are removed from the drill during the process.

Hole diameter and roundness are compared in Figures 8(a) and 8(b), respectively. While both fixing methods provided good dimensional accuracy, it can be noticed that the interference fit tool holder yielded superior overall results. The minor damage to tool wear identified in Figure 6(a) and 6(b), after drilling of 500 parts, did not, in fact, contribute to deterioration of hole accuracy in terms of diameter and roundness. Consistent with the results presented in Figure 4, both tools start to exhibit significant variations in diameter and roundness after approximately 7000 holes, which corresponds to the steep increase in the level of flank wear (Stage III). These results, in conjunction with those presented in Figure 7, indicate that while the higher stiffness produced by mounting with thermal interference did not lead to an increase in tool life by reducing the level of wear, it did contribute positively to the quality of the drilled holes in comparison to the tool fixed with the hydraulic tool holder.
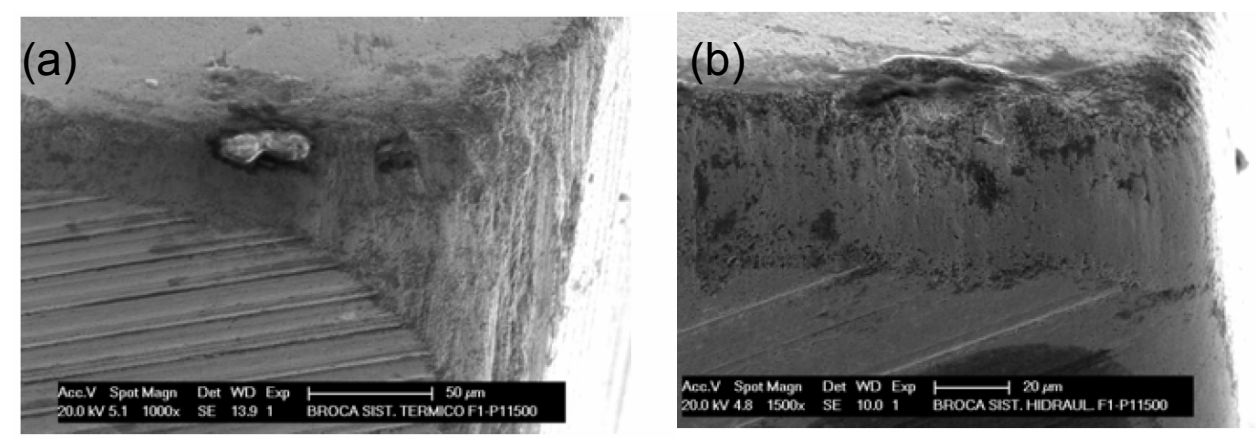

Figure 6. SEM images showing the outer corner flank wear land after drilling 11500 holes after removal of adhered material (1500x magnification): (a) shrink-fit and (b) hydraulic tool-holder

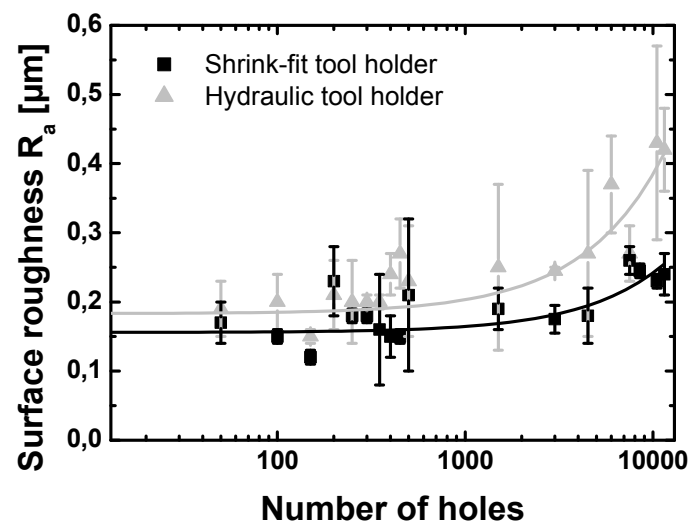

Figure 7. Evolution of surface roughness with respect to the number of drills for parts 1 to 11500 
(a)

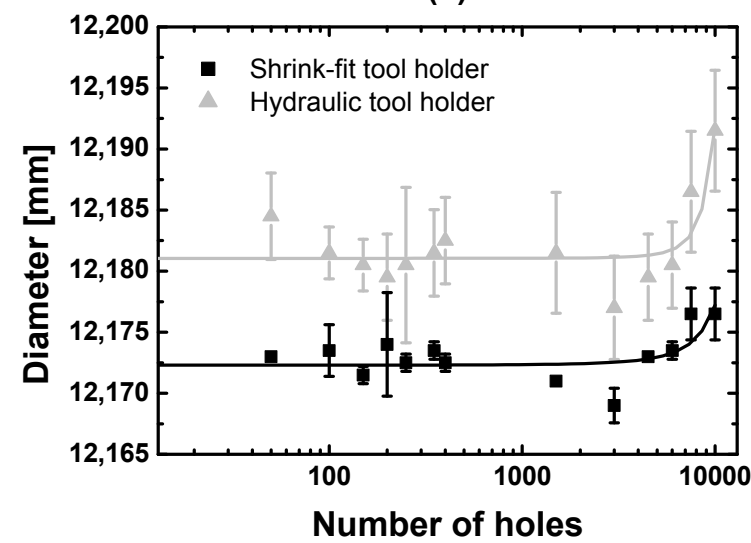

(b)

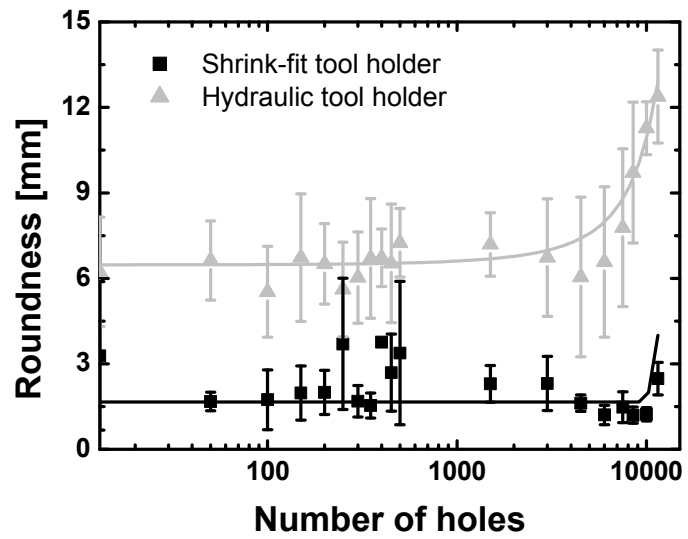

Figure 8. Evolution of hole geometry with respect to the number of drills for parts 1 to 11 500: (a) hole diameter and (b) roundness

\section{Conclusions}

The performance of interference-fit and hydraulic tool holders on the drilling of an Al-Si alloy was compared. The evolution of tool beating error and flank wear was shown to be similar for both fixing methods. The impact of this behavior on tool wear was analyzed by applying SEM and no significant differences could be detected for the fixing methods applied. Regarding hole quality, however, it was shown that the higher stiffness of the interference-fit method provided better results with respect to hole diameter, roundness and surface roughness.

\section{References}

Abele, E., Altintas, Y., \& Brecher, C. (2010). Machine Spindle Units. CIRP Annals - Manufacturing Technology, 59, 781-802. http://dx.doi.org/10.1016/j.cirp.2010.05.002

Arnone, M. (1998). High Performance Machining. Cincinnati: Hanser Gardner Publications (297-297).

Bhowmick, S., \& Alpas, A. T. (2008). The performance of hydrogenated and non-hydrogenated diamond-like carbon tool coatings during the dry drilling of 319Al. International Journal of Machine Tools \& Manufacture, 48, 802-814. http://dx.doi.org/10.1016/j.ijmachtools.2007.12.006

Coldwell, H. L., Dewes, R. C., Aspinwall, D. K., Renevier, N. M., \& Teer, D. G. (2004). The use of soft/lubricating coatings when dry drilling BS L168 aluminium alloy. Surface and Coatings Technology, 177-118, 716-726. http://dx.doi.org/10.1016/j.surfcoat.2003.08.012

Cotterell, M. G., \& Kelly, J. F. (2002). Minimal lubrication machining of aluminum alloys. Journal of Materials Processing Technology, 120, 327-334. http://dx.doi.org/10.1016/S0924-0136(01)01126-8

Doyle, E. D., Stevens, K. T., \& Thomas, A. (1986). The potential for improved life of cutting tools by coating with titanium nitride applied by physical vapour deposition, in: Proceedings of the Third International Conference on Manufacturing Engineering, Newcastle, August 4-6, 57-61.

Ertunc, H. M., \& Oysu, C. (2004). Drill wear monitoring using cutting force signals. Mechatronics, 14, 533-548. http://dx.doi.org/10.1016/j.mechatronics.2003.10.005

Fiedler, U., \& Würz, T. (2001). Fixação e balanceamento de ferramentas. Máquinas e Metais, 421, 24-37. (In Portuguese)

Harris, S. G., Doyle, E. D., Vlasveld, A. C., Audy, J., \& Quick, D. (2003). A study of the wear mechanisms of $\mathrm{Ti}_{1-\mathrm{x}} \mathrm{Al}_{\mathrm{x}} \mathrm{N}$ and $\mathrm{Ti}_{1-\mathrm{x}-\mathrm{y}} \mathrm{Al}_{\mathrm{x}} \mathrm{Cr}_{\mathrm{y}} \mathrm{N}$ coated high-speed steel twist drills under dry machining conditions. Wear, 254, 723-734. http://dx.doi.org/10.1016/S0043-1648(03)00258-8

Houming, Z., Chengyong, W., \& Zhenyu, Z. (2008). Dynamic characteristics of conjunction of lengthened shrink-fit holder and cutting tool in high-speed milling. Journal of Material Processing Technology, 207, 154-162. http://dx.doi.org/10.1016/j.jmatprotec.2007.12.083

Hu, J., \& Chou, K. (2007). Characteristics of cutting tool wear-land contact. Wear, 263, 1454-1458. http://dx.doi.org/10.1016/j.wear.2007.01.080 
Kalidas, S., De Vor, R. E., \& Kapoor, S. G. (2001). Experimental investigation of the effect of drill coatings on hole quality under dry and wet drilling conditions. Surface and Coating Technology, 148, 117-128. http://dx.doi.org/10.1016/S0257-8972(01)01349-4

Nouari, M., List, G., Girot, F., \& Géhin, D. (2005). Effect of machining parameters and coating on wear mechanisms in dry drilling of aluminium alloys. International Journal of Machine Tools \& Manufacture, 45, 1436-1442. http://dx.doi.org/10.1016/j.ijmachtools.2005.01.026

Schmitz, T. L., Powell, K., Won, D., Duncan, G. S., Sawyer, W. G., \& Ziegert, J. C. (2007). Shrink fit holder connection stiffness/damping modeling for frequency response prediction in milling. International Journal of Machine Tools \& Manufacture, 47, 1368-1380. http://dx.doi.org/10.1016/j.ijmachtools.2006.08.009

Schulz, H. (1998). Hoch gesch windig ke its bearbeitung - High-Speed Machining. München: Carl Hansen Verlag, 286-286.

Wain, N., Thomas N. R., Hickman D., Walbank, J., \& Teer, D. G. (2005). Performance of low-friction coating in the dry drilling of automotive Al-Si alloys. Surface \& Coating Technology, 200, 1885-1892. http://dx.doi.org/10.1016/j.surfcoat.2005.08.016

Trent, E. M., \& Wright, P. K. (2000). Metal Cutting $4^{\text {th }}$ Ed. Boston: Butterworth-Heinemann (254-258).

Zhang, Y., McClain, B., \& Fang, X. D. (2000). Design of interference fits via finite element method, International Journal of Mechanical Sciences, 42, 1835-1850. http://dx.doi.org/10.1016/S0020-7403(99)00072-7 